\title{
Improving Detection of Atrial Fibrillation After Transient Ischaemic Attack and Stroke
}

\author{
Dr Madhura Ghosh ${ }^{1}$, Dr Nichola Lochrie², Dr Seemin Mahmood³, Dr Enas Lawrence ${ }^{3}$, Dr Yi-Yen Karen Kee \\ 1. Imperial College Healthcare NHS Trust, Medicine, London, United Kingdom \\ . St George's University Hospital, Care of the Elderly, London, United Kingdom \\ Croydon University Hospital, Stroke Department, Care of the Elderly, Croydon, United Kingdom
}

\section{Introduction}

Atrial fibrillation (AF) is a known risk factor for embolic stroke and has been correlated to more severe strokes. Improved detection of AF reduces the risk of future stroke, potentially reducing the burden of disease for the patient and financially for the health service. Studies have shown that AF detection rates are highest close to the event ${ }^{1}$, underlining the need for prompt diagnosis.

Newer Adhesive Ambulatory ECG patch devices (AAECG) may offer alternatives to traditional cardiac telemetry. This pragmatic study aimed to compare AAECG (Zio XT device) against traditional 24 hour ambulatory monitoring.

\section{Methods and Patients}

30 patients with minor stroke or TIA were recruited prospectively from the TIA Clinic. Patients with a stroke syndrome but no evidence of intracerebral haemorrhage, known atrial fibrillation or cardiac arrthymias were included.

\begin{tabular}{|c|c|c|c|c|c|}
\hline & Number & Percentage & & Female & Male \\
\hline Male & 10 & $33.30 \%$ & \multirow{2}{*}{$\begin{array}{l}\text { Average } \\
\text { age }\end{array}$} & \multirow{2}{*}{63.1} & \multirow{2}{*}{59.8} \\
\hline Female & 20 & $66.6 \% \%$ & & & \\
\hline Stroke & 9 & $30 \%$ & Median & 61 & 57 \\
\hline TIA & 21 & $70 \%$ & UQ & 75.5 & 67.75 \\
\hline DWI+ve & 17 & $56.70 \%$ & LQ & 52.75 & 52.5 \\
\hline
\end{tabular}

\section{Results}

- $\mathrm{AF}$ (>30 seconds) was detected in 1 patient using the AAECG and none on the Holter.

- 2 patients were found to have other significant arrhythmias and pauses on the AAECG.

- Investigations were completed for 29 patients from the AAECG compared to 18 from Holter.

- Patients waited a median of 59 days for the Holter (range 14-102days). All Holter monitors were completed for 24 hours and the AAECG for a median of 13 days and 7 hours.

- All AAECG reports were available in clinic compared to 6 from the Holter

- Cost of the investigation plus follow up was $£ 367$ and $£ 440$ for a Holter and an AAECG respectively.
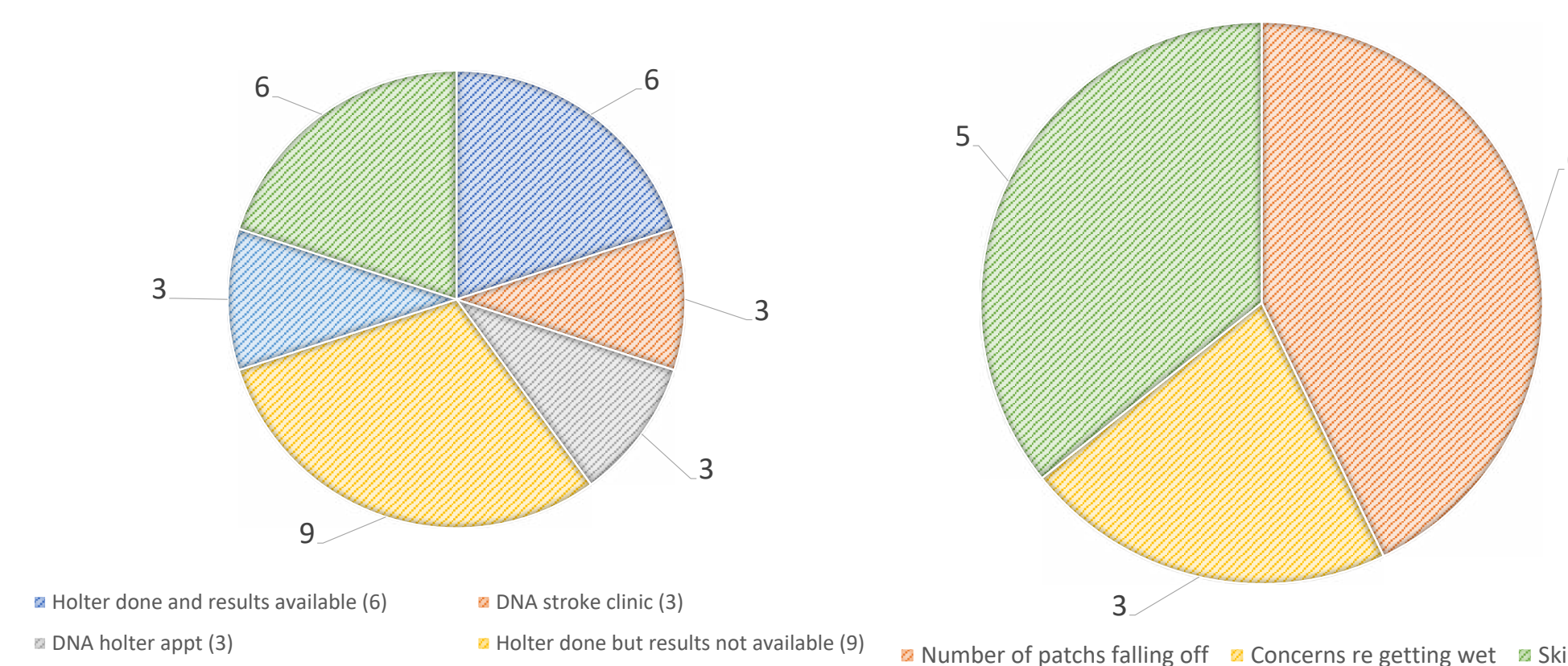

Qualitative data gathered showed some issues with the AAECG, as shown above.

\section{Conclusions}

Although the Zio system is more expensive in operational costs, it provided a more comprehensive follow up, and allowed timely investigation/management. Nearly half the patients attending the follow up clinic did not have Holter results because of administrative issues. Additionally, a significant delay between recruitment and monitoring was observed in Holter monitoring, and is known to have a lag time in the NHS ${ }^{2}$. As the pick-up rate has been shown to be highest in the initial 10 days following an event ${ }^{1}$, this lag time represents a proportion of affected patients who are not receiving treatment due to delays in investigations. The use of AAECG could allow services to offer "one-stop" TIA clinics where all investigations and clinical review can be done on the same day with a virtual or telephone follow up. Studies have shown that these can not only be cheaper ${ }^{3}$, but also have knock on effects on ensuring better compliance with attendance of future clinics ${ }^{4}$.

The increasing availability of economically viable portable medical technology has the potential to improve patient care, both through better patient access \& the opportunity for diagnosis.

\section{References}

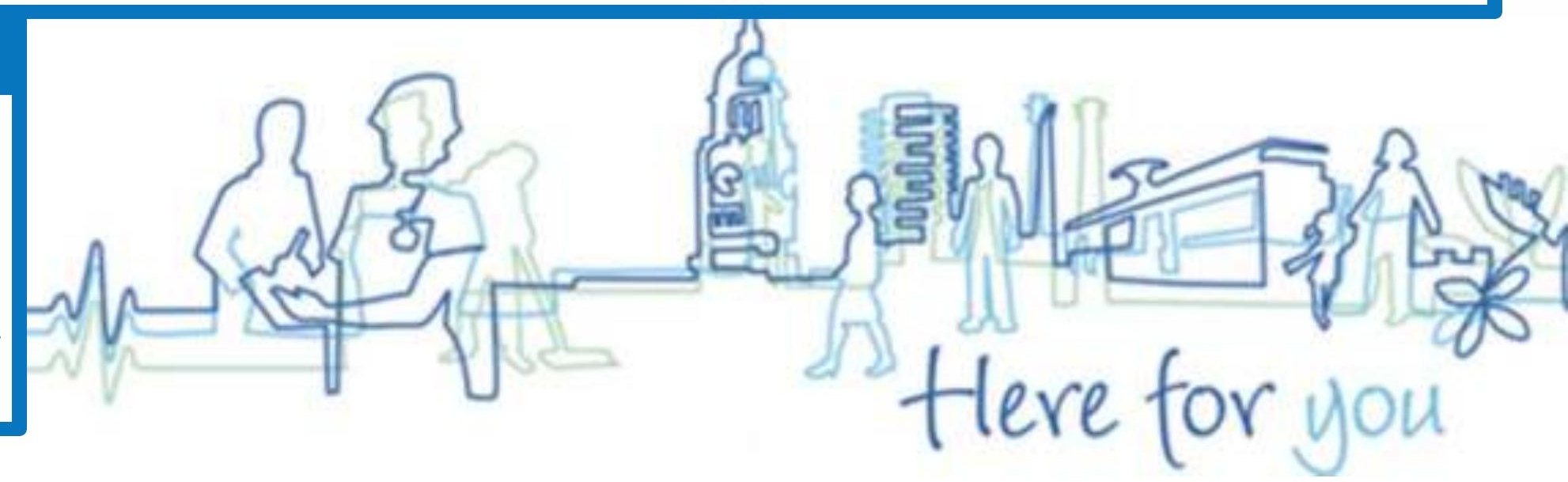

